\title{
Editorial
}

\section{Bisphenol A in Hemodialysis Patient: An Open Question}

\author{
Mauro Neri ${ }^{a}$ b \\ ${ }^{a}$ Department of Nephrology, Dialysis and Transplantation, International Renal Research Institute, San Bortolo \\ Hospital, and ${ }^{\mathrm{b}}$ Department of Management and Engineering, Università degli Studi di Padova, Vicenza, Italy
}

The debate on health effects of bisphenol A (BPA) is still on and controversial. The concept of BPA as endocrine disruptor on humans has been largely discussed and BPA mechanisms of metabolization have been studied and partially clarified [1]. While several studies have described BPA accumulation as a consequence of food and nutrient intake and oral exposure, the analysis of risks associated to direct elution in blood of BPA from extracorporeal circuits in acute and chronic hemodialysis is still a matter of research.

End-stage kidney disease (ESKD) patients undergoing extracorporeal hemodialysis are subject to potentially negative effects from high BPA blood concentrations due to blood contact with artificial surfaces. Two main reasons for this problem are as follows:

(1) The BPA release from polymeric medical disposables (polycarbonate, polysulfone, polyester, PVC) used in hemodialysis can be significant;

(2) The irreversible kidney damage in ESKD amplifies the accumulation of BPA in the systemic circulation due to reduced renal clearance.

It has been demonstrated that BPA concentrations inversely correlate with renal function $[2,3]$. However, till now no adverse effects have been ascribed to BPA in dialysis patients and it is unknown whether lowering BPA

\section{KARGER}

E-Mail karger@karger.com

www.karger.com/bpu concentration in these patients may result in improved clinical outcomes.

In such a context, the publication of Turgut et al. [4] provides some information in the complex process of understanding of the impact of BPA in hemodialysis patients.

The authors confirmed that BPA baseline levels in hemodialysis patients are significantly high and BPA is released in significant quantity from BPA containing plastic disposables placed in contact with blood at every dialysis session $(37 \%$ increase in plasma concentration measured by HPLC at the end of the dialysis session). Various factors may influence the concentration of BPA: treatment time, chemical and geometrical characteristics of the filter [5], blood and dialysate flow, transmembrane removal by diffusion and convection, membrane adsorption, shear rate and blood line compression in the pump segment.

The authors also investigated the possible associations between BPA concentrations and patients clinical characteristics. In particular, they found that predialysis serum BPA levels were significantly higher in patients with diabetes than those without diabetes although postdialysis levels were similar in both groups. The authors conclude that higher exposure to BPA may represent a factor contributing to the development of diabetes and diabetic
(C) 2016 S. Karger AG Basel

0253-5068/16/0421-0075\$39.50/0
Dr. Mauro Neri

Department of Nephrology, Dialysis and Transplantation

International Renal Research Institute of Vicenza

Viale Rodolfi 37, IT-36100 Vicenza (Italy)

E-Mail neri.mauro@gmail.com 
kidney disease. On the other hand, no association was found between age, body mass index, duration of hemodialysis, systolic and diastolic pressure, dose of erythropoietin, hemoglobin and Kt/V.

Longer follow-up will probably be needed in order to explore if BPA may have a long-term negative influence on hemodialysis patients. Among potentially negative effects of BPA on this population, cardiovascular risk [6], blood pressure increase [7] and monocyte cytotoxicity [8] have been investigated, but longer peri- ods of observation are necessary to confirm these effects.

For these reasons, till date, there is still insufficient evidence to set cut-off levels or to link BPA to any harmful effect in hemodialysis patients. The availability of BPAfree materials should, however, be stimulated by producers of dialysis disposable. With these new materials, a long-term comparison will probably be possible and it will help elucidating the effective role of BPA on clinical outcomes in hemodialysis.

\section{References}

1 Völkel W, Colnot T, Csanády GA, Filser JG, Dekant W: Metabolism and kinetics of bisphenol A in humans at low doses following oral administration. Chem Res Toxicol 2002; 15:1281-1287.

2 Krieter DH, Canaud B, Lemke HD, Rodriguez A, Morgenroth A, von Appen K, Dragoun GP, Wanner C: Bisphenol A in chronic kidney disease. Artif Organs 2013;37:283290.

3 Murakami K, Ohashi A, Hori H, Hibiya M, Shoji Y, Kunisaki M, Akita M, Yagi A, Sugiyama $\mathrm{K}$, Shimozato S, Ito $\mathrm{K}$, Takahashi $\mathrm{H}$, Takahashi K, Yamamoto K, Kasugai M, Kawamura N, Nakai S, Hasegawa M, Tomita
M, Nabeshima K, Hiki Y, Sugiyama S: Accumulation of bisphenol A in hemodialysis patients. Blood Purif 2007;25:290-294.

4 Turgut F, Okur R, Yaprak M, Ozsan M, Ustun I, Gokce C: Higher serum bisphenol A levels in diabetic hemodialysis patients. Blood Purif 2016;42:75-80.

5 Bosch-Panadero E, Mas S, Sanchez-Ospina D, Camarero V, Pérez-Gómez MV, Saez-Calero I, Abaigar P, Ortiz A, Egido J, González-Parra E: The choice of hemodialysis membrane affects bisphenol A levels in blood. J Am Soc Nephrol 2015;pii:ASN.2015030312.

6 Shankar A, Teppala S, Sabanayagam C: Bisphenol A and peripheral arterial disease: re- sults from the NHANES. Environ Health Perspect 2012;120:1297-1300.

7 Saura M, Marquez S, Reventun P, Olea-Herrero N, Arenas MI, Moreno-Gómez-Toledano R, Gómez-Parrizas M, Muñóz-Moreno C, González-Santander M, Zaragoza C, Bosch RJ: Oral administration of bisphenol A induces high blood pressure through angiotensin II/CaMKII-dependent uncoupling of eNOS. FASEB J 2014;28:4719-4728.

8 Neri M, Virzì GM, Brocca A, Garzotto F, Kim JC, Ramponi F, de Cal M, Lorenzin A, Brendolan A, Nalesso F, Zanella M, Ronco C: In vitro cytotoxicity of bisphenol A in monocytes cell line. Blood Purif 2015;40:180-186. 